\title{
Using a donut dressing to prevent pressure necrosis in heel reconstruction
}

Sir,

Local flaps, free flaps and skin grafts have been used for reconstruction of tissue loss from the heel. Efforts to minimise post-operative oedema with foot elevation must be balanced, with care taken to avoid direct pressure on the reconstruction, subsequent impaired tissue perfusion and pressure-related ischemia.

Soft tissue reconstructions of the posterior heel area may be compromised by external compression, causing partial flap necrosis. ${ }^{[1,2]}$ Limb elevation is commonly performed using pillows or even a Braun frame. These methods require the patient to remain in a relatively immobile position, or fail if the patient's limb slips off the supports. Other pressure reducing systems have been described, but are more complex and not readily available. ${ }^{[3]}$

We reported the case of a 23-year-old man, who sustained extensive full thickness burns involving his lower limbs. He had major tissue loss of the left foot, and a free latissimus dorsi muscle flap was used to cover the defect [Figure 1]. We had used a donut-shaped dressing to provide support at the mid calf level. This was achieved by using layers of Dressing Gamgee (Unisurge International Ltd.), which were wrapped around the leg at the mid-calf level, until approximately $25 \mathrm{~cm}$ thick. The 'donut' created was incorporated into the definitive leg dressing with a Cotton Crepe Bandage (Hospicrepe ${ }^{\circledR}$ ) and a tap, to secure its position [Figure 2]. As the dressing

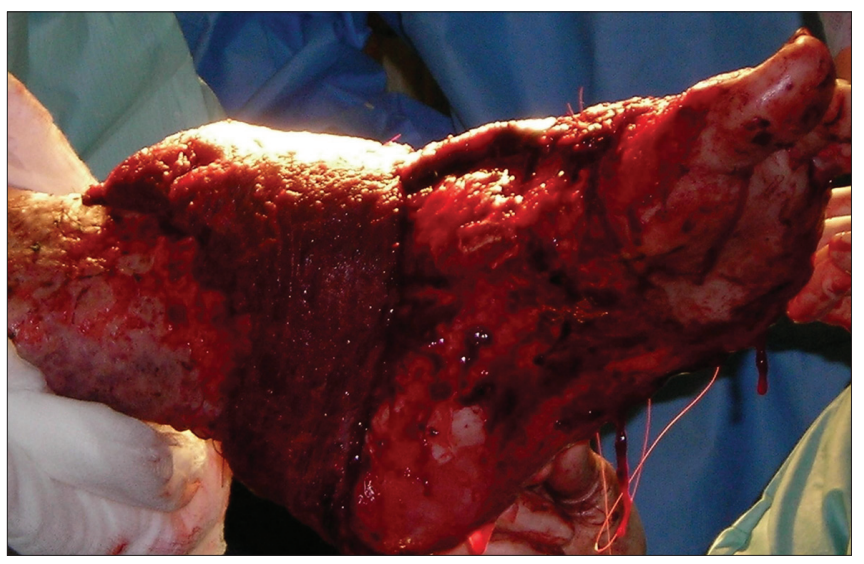

Figure 1: Free latissimus dorsi muscle flap to reconstruct major tissue loss from the back of heel and dorsum of the left foot 
Table 1: Materials used for each dressing

\begin{tabular}{lcccc}
\hline Dressing material & Dimension & Price / one & Company & Number used \\
\hline Dressing Gamgee & $90 \mathrm{~cm} \times 45 \mathrm{~cm}$ & $£ 1.70$ & Unisurge International Ltd. & 5 \\
Cotton Crepe Bandage & $15 \mathrm{~cm} \times 450 \mathrm{~cm}$ & $£ 1.98$ & Hospicrepe $^{\circledR}$ & 4 \\
\hline
\end{tabular}

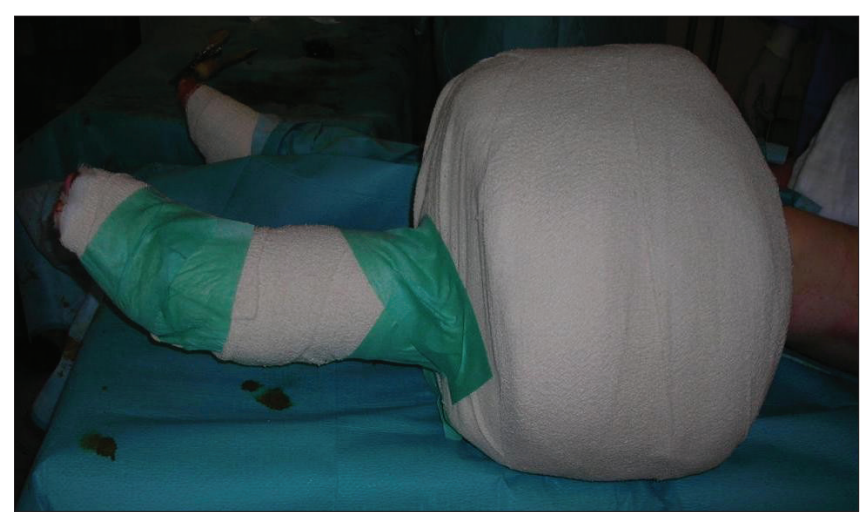

Figure 2: Donut Dressing at the mid calf to protect heel reconstruction



Figure 3: Complete wounds healing, three month follow-up

could rotate with patient movement, this technique was effective in maintaining continuous elevation not only when the patient was supine, but also when the patient was being turned, and if the patients turned on their side during sleep. It also prevented the patients crossing their legs and inadvertently causing compression. This dressing protected the free flap in the first ten days. No pressure necrosis or equinus deformity was reported in the foot and the wound completely healed [Figure 3]. This dressing was convenient and tolerated well by the patient. Also this 'Donut Dressing' was easy to create within few minutes and was cost effective [Table 1].

\section{Odhran P. Shelley, Azzam S. Farroha}

St Andrews Centre for Plastic Surgery and Burns, Chelmsford, UK

Correspondence to: Mr. Azzam S. Farroha, Senior Fellow, St Andrews Centre for Plastic Surgery and Burns, Broomfield Hospital, Chelmsford, CM1 7ET, UK. E-mail: Azzam.farroha@meht.nhs.uk

\section{REFERENCES}

1. Yucel A, Senyuva C, Aydin Y, Cinar C, Guzel Z. Soft-tissue reconstruction of sole and heel defects with free tissue transfers. Ann Plast Surg 2000;44:259-68.

2. Erdmann MW, Court-Brown CM, Quaba AA. A five year review of islanded distally based fasciocutaneous flaps on the lower limb. Br J Plast Surg 1997;50:421-7.

3. Zgonis T, Roukis T. Off-Loading Large Posterior Heel Defects After Sural Artery Soft-Tissue Flap Coverage With a Stacked Taylor Spatial Frame Foot Plate System. Oper Tech Orthop 2006:16:32-7.

\begin{tabular}{|l|l|}
\multicolumn{2}{c|}{ Access this article online } \\
\hline Quick Response Code: & Website: \\
\hline
\end{tabular}

